\title{
Posterior vertebral column subtraction osteotomy for the treatment of tethered cord syndrome: review of the literature and clinical outcomes of all cases reported to date
}

\author{
Patrick C. Hsieh, M.D., ${ }^{1}$ Christopher J. Stapleton, B.S., ${ }^{1,2}$ Pavel Moldavskiy, B.S., 1 \\ Tyler R. Koski, M.D., ${ }^{3}$ Stephen L. Ondra, M.D., ${ }^{3}$ Ziya L. GoKaslan, M.D., 4 \\ and Charles Kuntz IV, M.D. 5 \\ ${ }^{\prime}$ Department of Neurological Surgery, University of Southern California, Keck School of Medicine, Los \\ Angeles, California; ${ }^{2}$ Harvard-M.I.T. Division of Health Sciences and Technology, Harvard Medical School, \\ Boston, Massachusetts; ${ }^{3}$ Department of Neurological Surgery, Northwestern University Feinberg School of \\ Medicine, Chicago, Illinois; ${ }^{4}$ Department of Neurosurgery, Johns Hopkins University School of Medicine, \\ Baltimore, Maryland; and Department of Neurosurgery, Mayfield Clinic and Spine Institute, University of \\ Cincinnati, Ohio
}

Tethered cord syndrome (TCS) is a debilitating condition of progressive neurological decline caused by pathological, longitudinal traction on the spinal cord. Surgical detethering of the involved neural structures is the classic method of treatment for lumbosacral TCS, although symptomatic retethering has been reported in $5 \%-50 \%$ of patients following initial release. Subsequent operations in patients with complex lumbosacral dysraphic lesions are fraught with difficulty, and improvements in neurological function are modest while the risk of complications is high. In 1995, Kokubun described an alternative spine-shortening procedure for the management of TCS. Conducted via a single posterior approach, the operation relies on spinal column shortening to relieve indirectly the tension placed on the tethered neural elements. In a cadaveric model of TCS, Grande and colleagues further demonstrated that a 15-25-mm thoracolumbar subtraction osteotomy effectively reduces spinal cord, lumbosacral nerve root, and filum terminale tension. Despite its theoretical appeal, only 18 reports of the use of posterior vertebral column subtraction osteotomy for TCS treatment have been published since its original description. In this review, the authors analyze the relevant clinical characteristics, operative data, and postoperative outcomes of all 18 reported cases and review the role of posterior vertebral column subtraction osteotomy in the surgical management of primary and recurrent TCS. (DOI: 10.3171/2010.4.FOCUS1070)

KEY WORDS $\quad$ tethered cord syndrome $\quad \bullet$
posterior vertebral column subtraction osteotomy $\quad \bullet \quad$ review

$\mathrm{L}$

UMBOSACRAL TCS describes a constellation of clinical signs and symptoms caused by abnormal longitudinal traction on the caudal end of the spinal cord (Fig. 1). ${ }^{55}$ The condition results from a wide array of congenital and acquired pathological processes, the majority of which act to anchor the spinal cord within the lumbosacral region of the spinal canal. ${ }^{1,13}$ Common presenting neurological signs and symptoms are representative of the lumbosacral spinal cord levels affected: lower-extremity motor and sensory deficits; low-back,

\footnotetext{
Abbreviations used in this paper: $\mathrm{PVCSO}=$ posterior vertebral column subtraction osteotomy; rhBMP-2 = recombinant human bone morphogenetic protein $-2 ; \mathrm{TCS}=$ tethered cord syndrome; VB = vertebral body; $\mathrm{VCSO}=$ vertebral column subtraction osteotomy.
}

perineal, and lower-extremity pain; urinary and bowel incontinence; and sexual dysfunction. ${ }^{41}$ Since progressive neurological, orthopedic, and urological complications can arise in the absence of surgical intervention, prompt correction of the responsible lesion is necessary. ${ }^{1,7}$ Regardless of the procedure employed, the aim of surgery is to free the spinal cord and neural elements from tension to restore neurological function and prevent further deterioration. The traditional surgical treatment for TCS is a detethering procedure, although recurrent TCS develops in 5\%-50\% of patients following this initial operation. $2,10,14,21,31,33,35,38,44,54$ Due in part to scar formation and arachnoid adhesions, surgery for recurrent TCS is difficult and patients are at risk for developing further neurological injury, CSF leakage, pseudomeningocele, and wound complications. ${ }^{14,21,33,45}$ Recognizing 


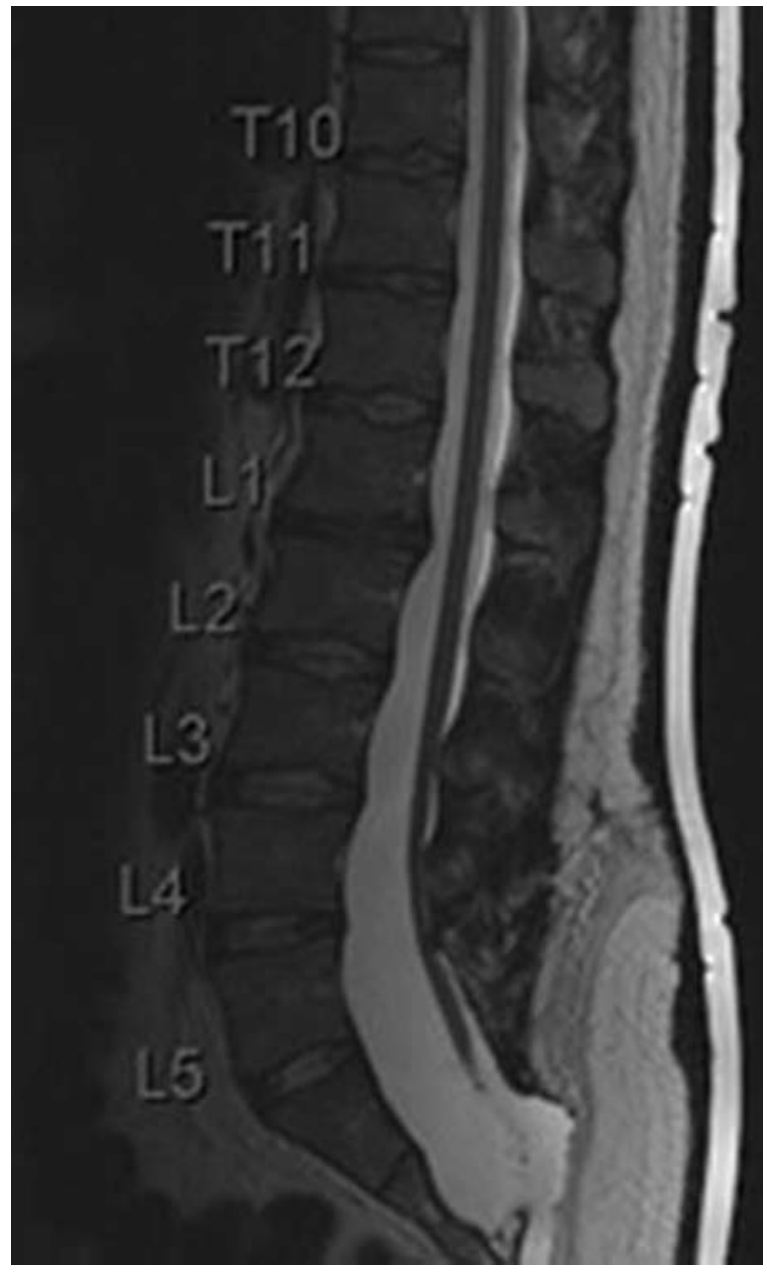

FIG. 1. Preoperative sagittal T2-weighted MR image demonstrating a low-lying conus medullaris and a recurrent tethered cord at L4-5 in a patient who had undergone previous multiple detethering surgeries. Reproduced with permission from Hsieh PC, et al: J Neurosurg Spine 10:278-286, 2009.

the drawbacks of these traditional detethering operations, Kokubun et al ${ }^{28,29}$ pioneered a spine-shortening procedure to relieve the longitudinal tension placed on the tethered neural elements without violating the dura. The operation is conducted via a posterior approach and a vertebral osteotomy is performed to facilitate spinal column shortening (Figs. 2 and 3). A detailed search of the neurosurgical and orthopedic literature reveals that posterior vertebral column subtraction osteotomy (PVCSO) has been used in 18 patients with TCS since its initial description. In this review, we provide an analysis of the relevant clinical characteristics, operative details, and postoperative outcomes in these patients and assess the role of PVCSO in the treatment of primary and recurrent TCS.

\section{Methods}

A PubMed (National Library of Medicine) search was performed to identify all articles pertaining to the use of spinal column shortening for the treatment of primary or recurrent lumbosacral TCS. Surgical series describing neurological outcomes were analyzed in detail and reference lists were reviewed for additional articles not identified in the original PubMed search. In the event that patient populations overlapped, ${ }^{28,51}$ the series with the larger cohort of patients was selected for further review. Pertinent clinical characteristics extracted from each report included patient age and sex, presenting neurological complaints, etiology of TCS, additional spinal pathology, and prior corrective procedures. Regarding operative data and postoperative outcomes, osteotomy level, length of spinal column shortening, duration of follow-up, recovered neurological functions, and residual neurological deficits were recorded.

Articles originally published in Japanese were translated to English by a professional translation service.

\section{Surgical Technique and Operative Details}

The following describes our approach to the PVCSO for a patient with primary or recurrent TCS without additional spinal column pathology. ${ }^{16}$ For optimal reduction of tension on the conus medullaris, filum terminale, and spinal cord, PVCSO is performed in the lower thoracic or upper lumbar levels. ${ }^{12}$ The specific osteotomy level, extent of bony resection, and degree of instrumentation should be determined on a patient-by-patient basis.

The patient is placed in the prone position on a Jackson Spinal Table. Neurophysiological monitoring, including somatosensory evoked potentials, motor evoked potentials, and free-run electromyography, is performed. ${ }^{42}$ A midline incision is made to expose the spine 2 levels rostral and 2 levels caudal to the planned PVCSO site (that is, T-12). We prefer to perform the osteotomy at the thoracolumbar junction. With the need to stabilize the spine 2 levels above and below to achieve immediate postoperative spinal stability for early mobilization, a T-11 or T-12 osteotomy allows one to spare more mobile segments in the lumbar spine. In addition, the regional spinal profile is neutral on both the sagittal and coronal plane. Therefore, a single-plane correctional maneuver to shorten the spinal column can avoid potential long-term decompensation of global spinal balance.

Following wide exposure of the T-12 segment, bilateral pedicle screws are implanted at T-10, T-11, L-1, and L-2, allowing for the placement of a relatively short yet biomechanically stable construct. To expose the lateral T-12 VB, the bilateral rib complexes, including the rib head and neck, and bilateral transverse processes at T-12 are removed (Fig. 2). Careful subperiosteal dissection along the lateral VB and lateral T-12 pedicle is performed until the anterior VB is visualized. A T11-12 discectomy is then carried out posterolaterally and the T-12 pedicles are removed entirely using a combination of rongeur and high-speed drilling. Prior to initiating the osteotomy, temporary rods are placed onto the pedicle screws to prevent translation of the spine while the posterior VB is osteotomized (Fig. 3). An approximate 20-mm T-12 VB osteotomy is created using a high-speed drill, beginning with the lateral walls and then moving in a posteroanterior fashion. The anterior VB wall is resected to the anterior longitudinal ligament, which is preserved; the posterior longitudinal ligament is sacrificed during removal of the posterior VB wall. Throughout the procedure, care 

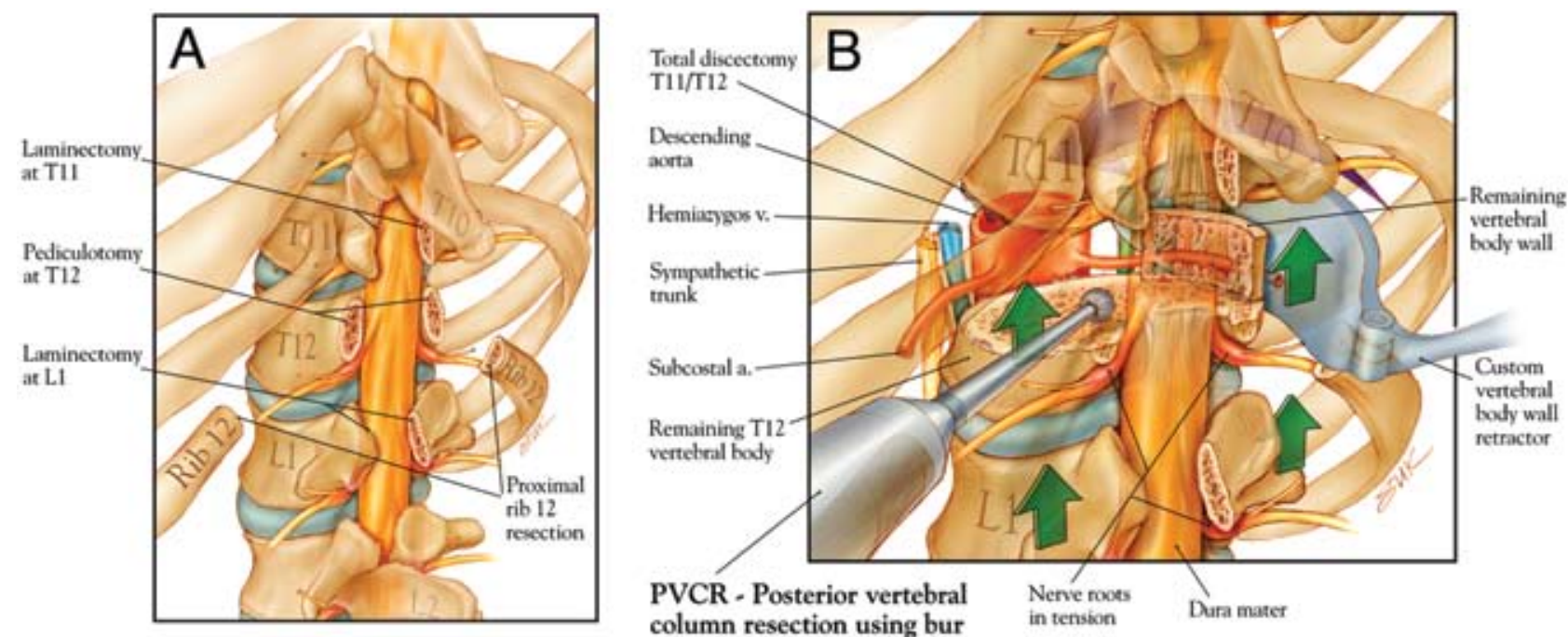

FIG. 2. Artist's illustrations of the PVCSO technique. A: Posterior illustration showing a T11-L1 laminectomy and resection of the proximal T-12 rib complex B: Posterior illustration of a T-12 PVCSO in which a high-speed drill is used to remove the T11-12 disc. a. = artery; v. = vein. Reproduced with permission from Hsieh PC, et al: J Neurosurg Spine 10:278-286, 2009.

is taken to avoid placing any unnecessary pressure on the thecal sac to prevent iatrogenic spinal cord injury.

Following completion of the VB resection, the temporary rods are replaced with 2 short segmental rods connected in parallel with domino connectors to facilitate safe, incremental closure of the osteotomy. Fusion across the 2 surfaces of the osteotomy can be achieved by placement of local autograft or iliac crest autograft. Alternatively, rhBMP-2 can be used to enhance bone fusion. ${ }^{8,9,46}$ The use of rhBMP-2 is an off-label application of this product. However, clinical studies have shown that rhBMP-2 results in high rate of fusion in multisegment spinal fusions for spinal deformity without the morbidity associated with iliac crest autograft harvest. Nevertheless, the cost and complications related to the rhBMP-2, including heterotopic bone growth and osteolysis, must be taken into account. The cephalad rod is secured onto the T-10 and T11 pedicle screws while the caudal rod is secured onto the L-1 and L-2 screws. The approximate 20-mm gap created by the T11-12 discectomy and T-12 osteotomy is now closed with serial compression through the domino connectors; temporary rods are replaced with permanent rods once final spinal column alignment is achieved (Fig. 3). Posterolateral arthrodesis is performed and the wound is closed in anatomical layers.

Many patients in whom PVCSO is indicated have undergone prior spinal column operations. In these cases, the PVCSO should be performed away from the prior operative site, as scar formation and arachnoid adhesions can place the neural structures at risk for injury during spinal shortening. ${ }^{40}$

\section{Tethered Cord Syndrome: Pathophysiology, Clinical Presentation, and Treatment Options}

Tethered cord syndrome is multifold in its etiology, yet what constitutes a tethered spinal cord has been the subject of much debate due in part to a limited understanding of the underlying pathophysiology. When Hoffman et al. ${ }^{15}$ published their account of 31 cases of TCS in 1976, only those patients with radiographic evidence of a low-lying conus medullaris secondary to a thick filum terminale were included in the analysis. ${ }^{1,58}$ Patients with lipomyelomeningoceles, myelomeningoceles, diastematomyelia, or other space-occupying lesions of the lumbosacral region were excluded from the study, despite Lichtenstein's observations in 1940 that lumbosacral masses can pathologically tether the caudal spinal cord. ${ }^{58}$ In 1981, Yamada et al. ${ }^{61}$ established experimentally in human and animal models of TCS that excessive stretching of the spinal neural elements impairs normal neuronal oxidative metabolism and overall electrophysiological functioning, therein providing a metabolic cause to a functional neurological effect. Their investigations further demonstrated that surgical release of the tethered neural structures restores oxidative metabolism with subsequent restoration of neurological function, a finding neurosurgeons had observed for many years despite little knowledge of the molecular pathophysiology. ${ }^{55}$ With a greater understanding of the subtle molecular defects present in TCS, the definition of a tethered spinal cord would gradually come to encompass the spectrum of lesions initially excluded from Hoffman and colleagues' analysis. . $^{1,56,59}$

The presenting signs and symptoms of TCS are almost as diverse as its causes, and although commonalities exist, the clinical presentation varies by age. ${ }^{41,60}$ Infants and children classically present with foot and spinal deformity and often have cutaneous manifestations of spinal dysraphism, such as lumbosacral capillary hemangiomas or tufts of hair. Urinary symptoms are common and manifest as excessive dribbling and delayed toilet training. Lower-extremity motor deficits typically result in gait abnormalities. Neurological symptoms are aggravated by growth spurts, which place excessive tension on the tethered spinal cord. ${ }^{7,42}$ In contrast to children, adults present more frequently with complaints of pain in the low back, anus and perineum, and lower extremities. Motor deficits 


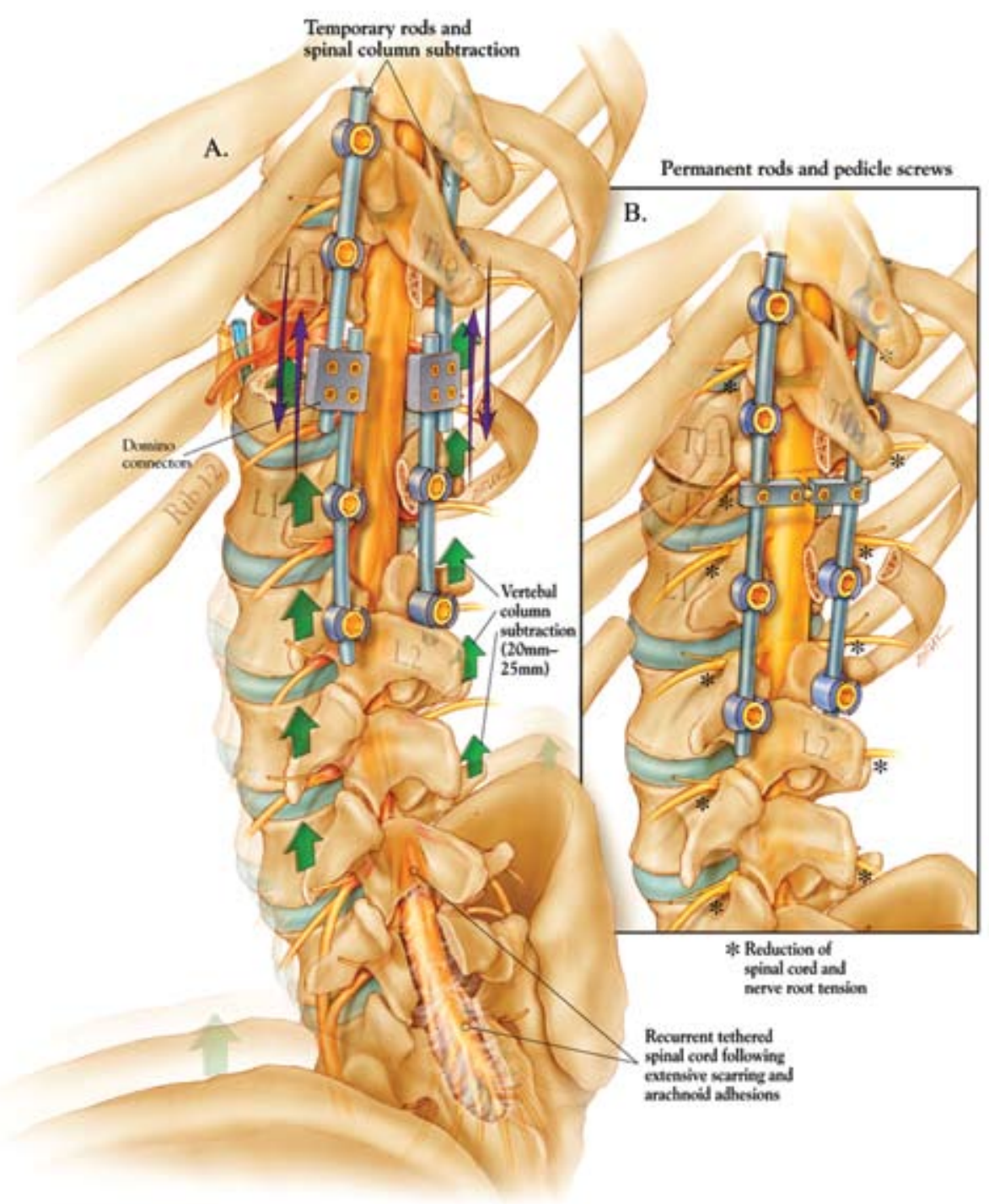

FIG. 3. Artist's illustrations of the surgical technique involved in osteotomy closure. A: Closure of the PVCSO is accomplished through careful serial compressions across the domino connectors. Note that closure of the osteotomy results in overall shortening of the spinal column and relaxation of distal spinal cord, nerve root, and terminal filum tension. B: The final instrumented spinal construct following closure of the PVCSO. Reproduced with permission from Hsieh PC, et al: J Neurosurg Spine 10:278-286, 2009.

manifest as pure lower-extremity weakness. As with children, urological symptoms are common and frequency, urgency, and incontinence are typical complaints. Factors that precipitate symptom onset include trauma, disc herniation, lumbar spondylosis, spinal canal stenosis, and excessive lumbar flexion or extension. ${ }^{13,20,41,57}$

In children and adults, surgical management of TCS is warranted at the first sign of neurological impairment..$^{31}$ The classic operation is a detethering procedure, in which the tethered neural structures are meticulously freed from their attachments, and this is followed by correction or removal of any associated pathology. In most cases, the filum terminale is severed or pathological adhesions around the distal spinal cord are detethered to reduce tension on the caudal spinal cord and associated neural elements. To avoid postoperative CSF leakage and pseudomeningocele formation, care is taken to close the dura in a watertight fashion. ${ }^{1,31,32}$ Most patients experience an improvement in their preoperative neurological symptoms following firsttime release; however, favorable recoveries decline with additional release operations. ${ }^{33,53}$ In severe cases of recurrent TCS, Blount et al. ${ }^{4}$ have advocated for complete spinal cord transection as a definitive measure of preserving more rostral neurological function. They have argued that traditional detethering procedures leave the freed neural structures approximated too closely to the incised dura, which allows for repeated retethering during the normal wound healing process. The procedure is reserved for selected cases in which the spinal cord and filum terminale are nonfunctional and in which the main goal of surgery is not to restore neurological function but to prevent further decline. Despite these available surgical options, a 


\section{Posterior vertebral column subtraction osteotomy for TCS}

nontrivial percentage of patients still suffer progressive neurological deterioration from recurrent TCS.

\section{Posterior Vertebral Column Subtraction Osteotomy}

Spine-shortening procedures were first used for the correction of various deformities of the spinal column. ${ }^{3,5,22,47-50}$ The operations were initially conducted via dual anterior and posterior approaches and consisted of either wedge osteotomies or VB resection for spinal column shortening. Following critical advances in the technology of spine instrumentation, a single posterior approach for spine-shortening operations was developed. ${ }^{29,47-49}$ Classic indications for spinal column shortening include severe scoliosis, kyphosis, and VB fractures..$^{19,23,29,43}$ In 1995, Kokubun ${ }^{28}$ described the use of a spine-shortening procedure performed via a posterior approach for the treatment of TCS in 2 patients. The operation was conducted in lieu of a traditional detethering procedure as a means of relieving pathological tension on the tethered spinal cord and nerve roots, and was the first report of an entirely extradural procedure for TCS treatment. Although only 1 patient experienced complete neurological recovery, the initial results were promising and provided cause for further investigation into this novel technique. Subsequently, using a cadaveric model of TCS, Grande et al. ${ }^{2}$ demonstrated that greater than $90 \%$ of the neural elements require release by traditional surgical detethering to achieve the same decrease in tension on the spinal cord, nerve roots, and filum terminale as a $15-25-\mathrm{mm}$ VCSO at the thoracolumbar junction. Since efficient release of the tension placed on the tethered neural structures is necessary for improved oxidative metabolism and electrophysiological functioning, ${ }^{61}$ PVCSO may be a preferable alternative to traditional detethering operations (Figs. 4 and 5).

\section{Case Series and Outcome Data}

Table 1 summarizes the relevant clinical characteristics of the patients described in previously published case reports that provided significant clinical data. There are currently a total of 18 patients who underwent PVCSO for TCS treatment with significant clinical data provided in the previous publications. . $^{16,22,28,34,37,39,51,52}$ The mean age at the time of surgery was 40 years (range $12-57$ years). Prior to PVCSO, 5 patients (28\%) underwent traditional detethering operations and 5 patients $(28 \%)$ underwent excision of the lumbosacral mass. Lumbosacral lipomyelomeningocele $(61 \%)$ and lumbosacral lipoma (28\%) were the most common causes of TCS. One patient $(6 \%)$ had a VB fracture and 1 patient (6\%) suffered from severe kyphoscoliosis with an intramedullary syrinx in addition to a tethered spinal cord. Lumbosacral spina bifida was identified in 5 patients $(28 \%)$. Presenting neurological symptoms included urinary dysfunction (94\%), lower-extremity sensory disturbances (89\%), lower-extremity motor disturbances and/or gait abnormalities (78\%), low-back and/or lower-extremity pain (72\%), bowel incontinence (11\%), and sexual dysfunction (11\%). In 2 instances, the decision to perform PVCSO was motivated by marked worsening of the patient's neurological status following a traditional detethering procedure; 34,39 in these cases, the duration to PVCSO was 3 months. In these patients, the primary goal of PVCSO was reportedly

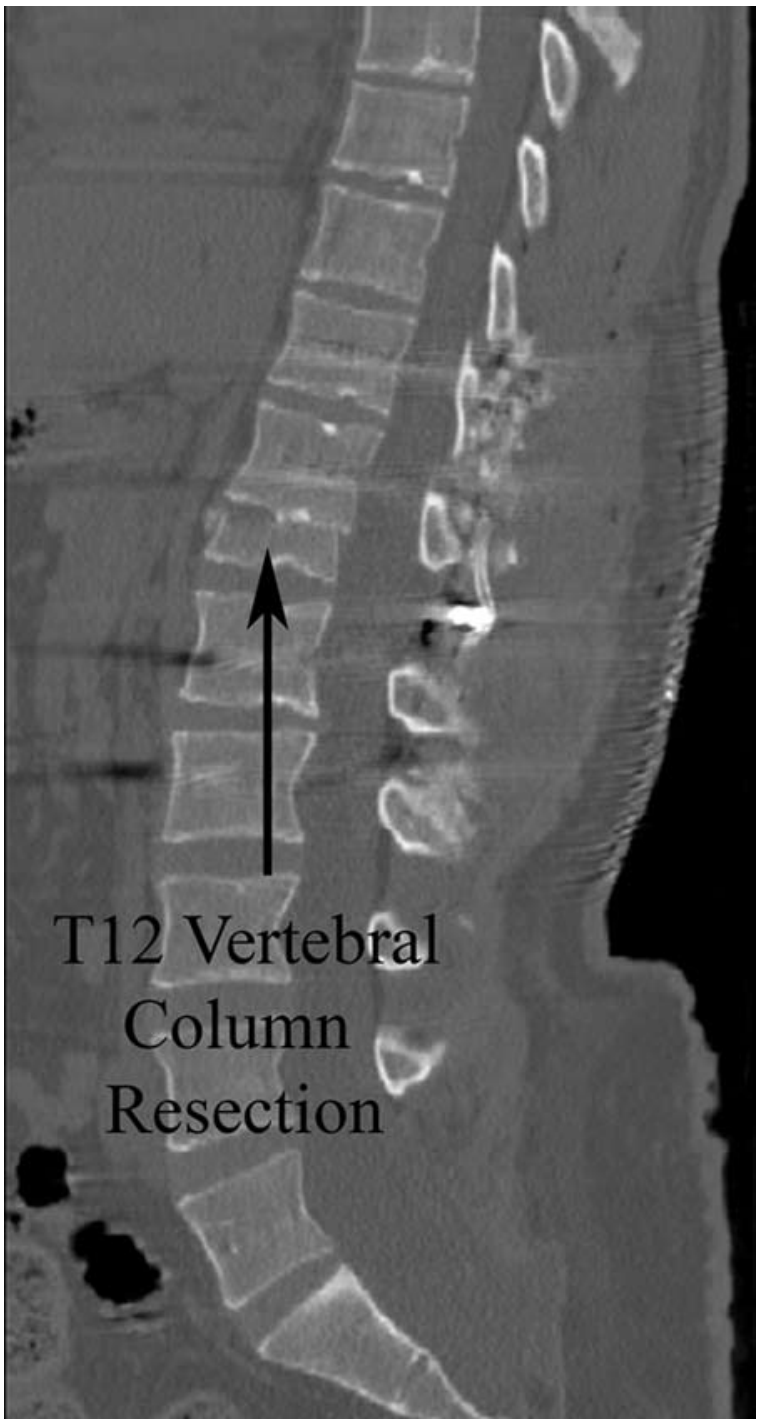

FIG. 4. Postoperative sagittal CT reconstruction demonstrating a T-12 PVCSO and closure of the osteotomy in anatomical alignment along the thoracolumbar junction. Reproduced with permission from Hsieh PC, et al: J Neurosurg Spine 10:278-286, 2009.

to prevent further neurological deterioration rather than to offer functional recovery.

Pertinent operative data and postoperative outcomes are summarized in Table 2. No intraoperative or immediate postoperative complications were reported. The vertebral osteotomy was performed at L-1 in 14 patients (78\%), at T-12 in 2 patients (11\%), and at T-9 and L-2 in 1 patient each (6\%). The length of spinal column shortening was reported for 16 patients (mean length $20.5 \mathrm{~mm}$ ). The mean follow-up duration was 3 years (range 6 months-10 years). Urinary dysfunction (17 cases) was the most common residual deficit, as only 3 patients $(18 \%)$ noted a full recovery of function. Two (12\%) of 17 patients with urological symptoms reported improvements, although deficits remained at the time of last follow-up. Twelve (86\%) of 16 patients with lower-extremity motor dysfunction improved and $8(50 \%)$ noted complete resolution of preoperative lower-extremity sensory symptoms. Nine patients 


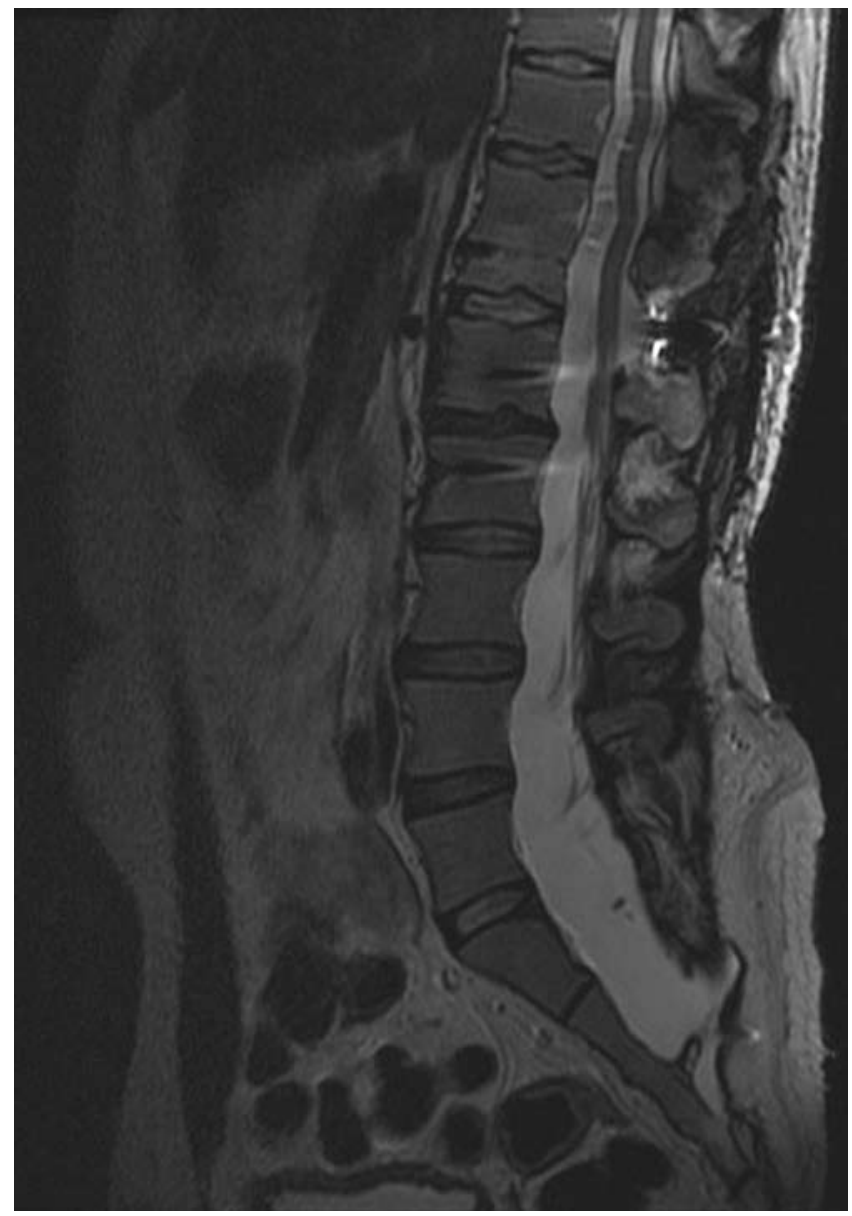

FIG. 5. Postoperative sagittal T2-weighted MR image obtained 1 year following PSVCO for TCS, showing relaxation of the distal spinal cord and cauda equina without evidence of spinal cord kinking. There is bone-on-bone approximation and fusion at the PVCSO site without subluxation or abnormal regional spinal alignment. Reproduced with permission from Hsieh PC, et al: J Neurosurg Spine 10:278-286, 2009.

(75\%) reported immediate low-back or lower-extremity pain relief following PVCSO. Two patients (100\%) reported improved sexual functioning, although only 1 regained complete erectile capabilities. Two patients (11\%) experienced little symptomatic or functional benefit from PVCSO. In these cases, however, the main aim of surgery was to prevent further worsening of the neurological condition, as each had experienced new-onset neurological dysfunction following a detethering operation shortly before undergoing spinal column shortening. Where reported, complete bone union at the osteotomy site was noted in all cases at the time of last follow-up..$^{16,22,28,37,39,51}$

\section{Discussion}

The surgical management of both primary and recurrent lumbosacral TCS is complex, yet without intervention patients will suffer progressive neurological, orthopedic, and urological decline. ${ }^{1,21,33}$ Several studies have evaluated the symptomatic and functional outcome of adults undergoing detethering procedures for primary lumbosacral
TCS and collectively indicate a 38.5\%-61\% improvement in urinary symptoms, a 44\%-70\% improvement in weakness/motor disturbances, and an $81 \%-91 \%$ improvement in pain following surgical detethering. ${ }^{11,17,20,31,41}$ Despite these encouraging outcomes, a reported $5 \%-50 \%$ of patients eventually experience symptomatic retethering, and patients who undergo multiple detethering operations do not share this same degree of success. ${ }^{31,33}$ Our review of the available outcome data in patients who have undergone PVCSO indicate that $28 \%$ exhibited improved urological symptoms, $86 \%$ recovered complete motor functioning, and $75 \%$ were relieved of debilitating back or lower-extremity pain. Although many factors preclude a direct comparison of the symptomatic and functional outcomes following traditional surgical detethering compared with PVCSO for TCS treatment, the outcomes, grossly, are similar. Regardless, we believe that the principal benefits of PVCSO over detethering operations will be in preserving the symptomatic and functional neurological improvements with lasting results and potentially obviating the need for future reoperations. However, longer follow-up results are needed from the PVCSO series to support this belief.

In the treatment of TCS, there are several advantages of PVCSO over detethering operations. First, direct manipulation of the neural structures is not required. Because traditional detethering procedures mandate careful dissection of the tethered spinal cord and affected neural elements away from the sites of adhesion, the risk of direct neurological injury is high. Operations for recurrent TCS may be additionally complicated by extensive scar formation and arachnoid adhesions, ${ }^{30}$ further elevating the likelihood of iatrogenic neurological injury. Second, because PVCSO is an entirely extradural operation, the risks associated with postoperative CSF leakage and pseudomeningocele formation can be largely avoided. Third, PVCSO reduces traction on the affected neural elements indirectly (Fig. 5). Given adequate bone union and a stable instrumented construct, the beneficial effects of spinal column shortening should remain permanent. As a result, patients may be able to expect sustained improvements in their neurological symptoms, and the risks and costs associated with reoperations may be avoided. These advantages are particularly relevant in patients who have undergone multiple intradural detethering procedures without success. It is our belief and practice that patients are considered for PVCSO only in recurrent cases of TCS without local mass effects or findings that are amendable to standard surgical detethering procedures. Nevertheless, our current literature review has shown that, in the Japanese literature, 5 patients have undergone primary PVCSO treatment for lumbosacral lipoma or lipomyelomeningocele with favorable outcomes. Future clinical studies with longer clinical follow-up periods will be necessary to determine if PVCSO can be as effective as the traditional detethering surgery in the primary surgical treatment for patients with TCS.

Despite the appeal of PVCSO for the treatment of primary and recurrent TCS, there are several theoretical disadvantages. First, as a result of extensive dissection and spinal manipulation, iatrogenic neurological injury may 







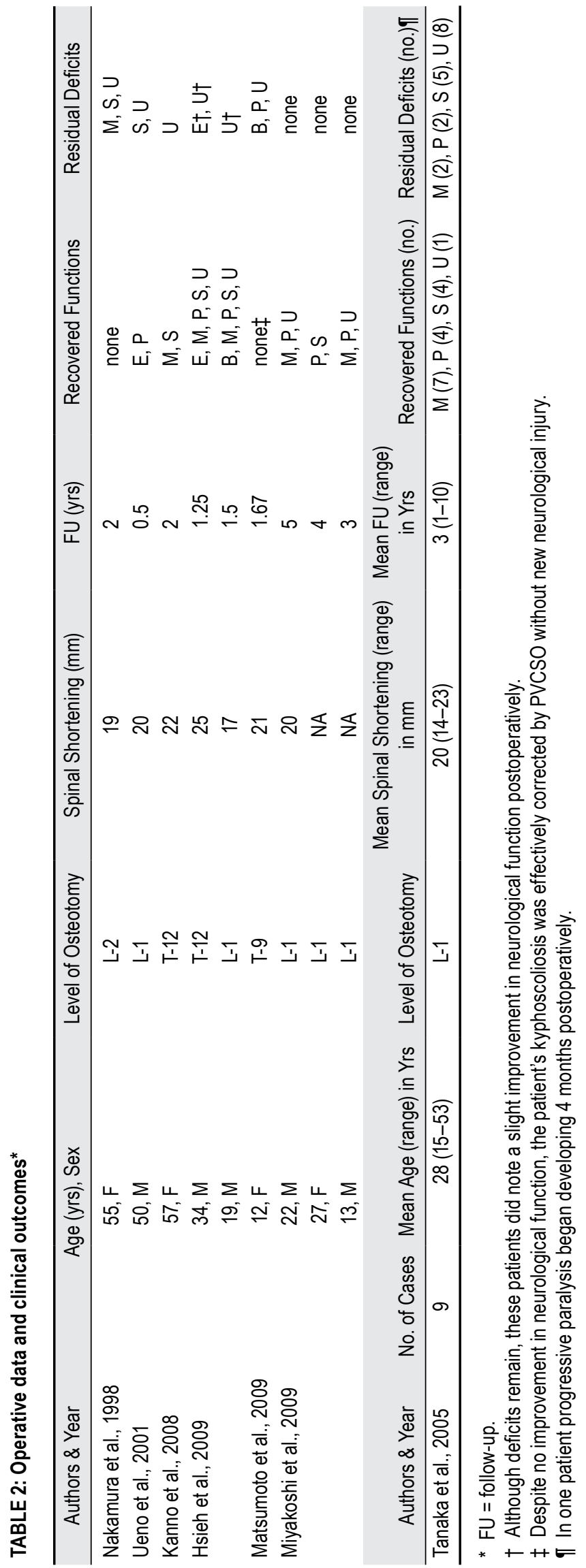

arise from excessive nerve root traction, dural violation, or exacerbation of prior spinal deformities. ${ }^{18,24} \mathrm{In}$ an analysis of the risk of neurological injury following lumbar pedicle subtraction osteotomy, reported by Buchowski et al., ${ }^{6} 3 \%$ of patients experienced permanent new-onset neurological deficits. Second, because the osteotomy involves all 3 spinal columns, the spine is highly unstable following PVCSO, and translation, subluxation, or misalignment can occur if the gap closure is inadequate, or if pseudarthrosis develops. Despite the use of an instrumented construct for spinal stabilization, pseudarthrosis has been found in $17 \%-24 \%$ of cases involving multisegmental, instrumented fusion. ${ }^{25-27}$ Such complications increase the risk of instrumentation failure, neurological injury, spinal deformity, and chronic back pain. The complication rate associated with a similar technique of pedicle subtraction osteotomy in deformity revisions can be as high as $50 \%$, but much of those complications are related to medical complications resulting from performing high-risk complex spinal surgeries in a more elderly population. Third, instrumented fusion of the spinal column is required with PVCSO. To ensure biomechanical stability, our protocol is to provide fixation 2 levels rostral and caudal to the osteotomy, necessitating a 4-level fusion. A multisegmented, instrumented fusion predisposes the patient to future disease in adjacent segments. ${ }^{36}$ Fourth, vertebral column resection requires extensive paraspinal dissection and the amount of perioperative blood loss is not trivial. This can be minimized with careful subperiosteal dissection along the VB wall, which reduces injury to segmental vessels. Despite these potential drawbacks and the inherent technical demands of the operation, the procedure can be performed safely and with acceptable surgical risks at experienced centers.

Our analysis of data obtained in 18 patients reported on in the literature indicates that PVCSO is a viable alternative to traditional detethering operations for the management of primary and recurrent TCS. Future outcome studies with larger sample sizes and long-term follow-up are needed to further clarify the risks and benefits of the procedure and to identify specific patient groups most likely to benefit from PVCSO.

\section{Conclusions}

Tethered cord syndrome is a progressively debilitating neurological condition caused by abnormal longitudinal traction on the caudal spinal cord. The classic treatment is surgical detethering, although rates of symptomatic retethering range from $5 \%-50 \%$. With subsequent operations, surgical complications increase while favorable neurological outcomes decrease. The present analysis indicates that PVCSO is a safe and effective alternative to traditional detethering operations for the treatment of primary and recurrent TCS. Not only does the procedure avoid the risks inherent in any intradural operation, but cadaveric studies also indicate that extensive surgical detethering is necessary to achieve results similar to those from a 15-25-mm thoracolumbar PVCSO. Because the use of PVCSO for TCS treatment is in its infancy, future studies with a larger number of patients and longer follow- 
up periods are needed to verify its efficacy and identify patients most likely to benefit from this novel approach.

\section{Disclosure}

Dr. Gokaslan has direct stock ownership in Spinal Kinetics and US Spine; additionally he receives fellowship support from AO North America, and he receives a stipend as an OA board member and an honorarium from AO North America. Dr. Ondra has direct stock ownership in and in a patent holder in material for Medtronic. Dr. Hsieh received an honorarium from Medtronic for teaching courses on minimally invasive spine surgery techniques. Mr. Stapleton is supported by the Sarnoff Cardiovascular Research Foundation Fellowship Award.

Author contributions to the study and manuscript preparation include the following. Conception and design: Hsieh, Koski, Ondra, Kuntz. Acquisition of data: Hsieh, Stapleton, Moldavskiy. Analysis and interpretation of data: Hsieh, Stapleton, Koski. Drafting the article: Hsieh, Stapleton, Moldavskiy. Critically revising the article: Hsieh, Stapleton, Koski, Gokaslan, Kuntz. Reviewed final version of the manuscript and approved it for submission: Hsieh, Gokaslan, Kuntz. Statistical analysis: Hsieh, Stapleton, Moldavskiy, Kuntz. Administrative/technical/material support: Koski, Ondra, Gokaslan. Study supervision: Hsieh, Koski, Ondra, Kuntz.

\section{References}

1. Agarwalla PK, Dunn IF, Scott RM, Smith ER: Tethered cord syndrome. Neurosurg Clin N Am 18:531-547, 2007

2. Archibeck MJ, Smith JT, Carroll KL, Davitt JS, Stevens PM: Surgical release of tethered spinal cord: survivorship analysis and orthopedic outcome. J Pediatr Orthop 17:773-776, 1997

3. Boachie-Adjei O, Bradford DS: Vertebral column resection and arthrodesis for complex spinal deformities. J Spinal Disord 4:193-202, 1991

4. Blount JP, Tubbs RS, Okor M, Tyler-Kabara EC, Wellons JC III, Grabb PA, et al: Supraplacode spinal cord transection in paraplegic patients with myelodysplasia and repetitive symptomatic tethered spinal cord. J Neurosurg 103 (1 Suppl): 36-39, 2005

5. Bradford DS, Tribus CB: Vertebral column resection for the treatment of rigid coronal decompensation. Spine 22:15901599,1997

6. Buchowski JM, Bridwell KH, Lenke LG, Kuhns CA, Lehman RA Jr, Kim YJ, et al: Neurologic complications of lumbar pedicle subtraction osteotomy: a 10-year assessment. Spine 32: 2245-2252, 2007

7. Bui CJ, Tubbs RS, Oakes WJ: Tethered cord syndrome in children: a review. Neurosurg Focus 23(2):E2, 2007

8. Burkus JK, Transfeldt EE, Kitchel SH, Watkins RG, Balderston RA: Clinical and radiographic outcomes of anterior lumbar interbody fusion using recombinant human bone morphogenetic protein-2. Spine 27:2396-2408, 2002

9. Dimar JR, Glassman SD, Burkus KJ, Carreon LY: Clinical outcomes and fusion success at 2 years of single-level instrumented posterolateral fusions with recombinant human bone morphogenetic protein-2/compression resistant matrix versus iliac crest bone graft. Spine 31:2534-2540, 2006

10. Filler AG, Britton JA, Uttley D, Marsh HT: Adult postrepair myelomeningocoele and tethered cord syndrome: good surgical outcome after abrupt neurological decline. Br J Neurosurg 9:659-666, 1995

11. Garcés-Ambrossi GL, McGirt MJ, Samuels R, Sciubba DM, Bydon A, Gokaslan ZL, et al: Neurological outcome after surgical management of adult tethered cord syndrome. Clinical article. J Neurosurg Spine 11:304-309, 2009

12. Grande AW, Maher PC, Morgan CJ, Choutka O, Ling BC, Raderstorf TC, et al: Vertebral column subtraction osteotomy for recurrent tethered cord syndrome in adults: a cadaveric study. J Neurosurg Spine 4:478-484, 2006

13. Gupta SK, Khosla VK, Sharma BS, Mathuriya SN, Pathak A, Tewari MK: Tethered cord syndrome in adults. Surg Neurol 52:362-370, 1999

14. Herman JM, McLone DG, Storrs BB, Dauser RC: Analysis of 153 patients with myelomeningocele or spinal lipoma reoperated upon for a tethered cord. Presentation, management and outcome. Pediatr Neurosurg 19:243-249, 1993

15. Hoffman HJ, Hendrick EB, Humphreys RP: The tethered spinal cord: its protean manifestations, diagnosis and surgical correction. Childs Brain 2:145-155, 1976

16. Hsieh PC, Ondra SL, Grande AW, O’Shaughnessy BA, Bierbrauer K, Crone KR, et al: Posterior vertebral column subtraction osteotomy: a novel surgical approach for the treatment of multiple recurrences of tethered cord syndrome. Technical note. J Neurosurg Spine 10:278-286, 2009

17. Hüttmann S, Krauss J, Collmann H, Sörensen N, Roosen K: Surgical management of tethered spinal cord in adults: report of 54 cases. J Neurosurg 95 (2 Suppl):173-178, 2001

18. Ikenaga M, Shikata J, Takemoto M, Tanaka C: Clinical outcomes and complications after pedicle subtraction osteotomy for correction of thoracolumbar kyphosis. J Neurosurg Spine 6:330-336, 2007

19. Ishibashi K, Ogawa S, Fujii G, Kokubun S: [Shortening osteotomy for burst fractures of the lumbar spine.] Orthop Surg Traumatol 45:769-774, 2002 (Jpn)

20. Iskandar BJ, Fulmer BB, Hadley MN, Oakes WJ: Congenital tethered spinal cord syndrome in adults. J Neurosurg 88: 958-961, 1998

21. Kang JK, Lee KS, Jeun SS, Lee IW, Kim MC: Role of surgery for maintaining urological function and prevention of retethering in the treatment of lipomeningomyelocele: experience recorded in 75 lipomeningomyelocele patients. Childs Nerv Syst 19:23-29, 2003

22. Kanno H, Aizawa T, Ozawa H, Hoshikawa T, Itoi E, Kokubun S: Spine-shortening vertebral osteotomy in a patient with tethered cord syndrome and a vertebral fracture. Case report. J Neurosurg Spine 9:62-66, 2008

23. Kawahara N, Tomita K, Baba H, Kobayashi T, Fujita T, Murakami $\mathrm{H}$ : Closing-opening wedge osteotomy to correct angular kyphotic deformity by a single posterior approach. Spine 26:391-402, 2001

24. Kawahara N, Tomita K, Kobayashi T, Abdel-Wanis ME, Murakami $\mathrm{H}$, Akamaru T: Influence of acute shortening on the spinal cord: an experimental study. Spine 30:613-620, 2005

25. Kim YJ, Bridwell KH, Lenke LG, Cho KJ, Edwards CC II, Rinella AS: Pseudarthrosis in adult spinal deformity following multisegmental instrumentation and arthrodesis. J Bone Joint Surg Am 88:721-728, 2006

26. Kim YJ, Bridwell KH, Lenke LG, Rhim S, Cheh G: Pseudarthrosis in long adult spinal deformity instrumentation and fusion to the sacrum: prevalence and risk factor analysis of 144 cases. Spine 31:2329-2336, 2006

27. Kim YJ, Bridwell KH, Lenke LG, Rinella AS, Edwards C II: Pseudarthrosis in primary fusions for adult idiopathic scoliosis: incidence, risk factors, and outcome analysis. Spine 30:468-474, 2005

28. Kokubun S: [Shortening spinal osteotomy for tethered cord syndrome in adults.] Spine Spinal Cord 8 (Suppl 12):5, 1995 (Jpn)

29. Kokubun S, Tanaka Y, Hoshikawa K, Sato T, Yamazaki S, Ishibashi K: [Shortening spinal osteotomy through posterior approach, and its applications.] Seikei Saigaigeka 46:447455, 2003 (Jpn)

30. Lagae L, Verpoorten C, Casaer P, Vereecken R, Fabry G, Plets $\mathrm{C}$ : Conservative versus neurosurgical treatment of tethered cord patients. Z Kinderchir 45 (1 Suppl 1):16-17, 1990

31. Lee GY, Paradiso G, Tator CH, Gentili F, Massicotte EM, Fe- 
hlings MG: Surgical management of tethered cord syndrome in adults: indications, techniques, and long-term outcomes in 60 patients. J Neurosurg Spine 4:123-131, 2006

32. Lee TT, Arias JM, Andrus HL, Quencer RM, Falcone SF, Green BA: Progressive posttraumatic myelomalacic myelopathy: treatment with untethering and expansive duraplasty. J Neurosurg 86:624-628, 1997

33. Maher CO, Goumnerova L, Madsen JR, Proctor M, Scott RM: Outcome following multiple repeated spinal cord untethering operations. J Neurosurg 106 (6 Suppl):434-438, 2007

34. Matsumoto M, Watanabe K, Tsuji T, Ishii K, Takaishi H, Nakamura M, et al: Progressive kyphoscoliosis associated with tethered cord treated by posterior vertebral column resection: a case report. Spine 34:E965-E968, 2009

35. McLone DG, La Marca F: The tethered spinal cord: diagnosis, significance, and management. Semin Pediatr Neurol 4: 192-208, 1997

36. Min JH, Jang JS, Jung BJ, Lee HY, Choi WC, Shim CS, et al: The clinical characteristics and risk factors for the adjacent segment degeneration in instrumented lumbar fusion. J Spinal Disord Tech 21:305-309, 2008

37. Miyakoshi N, Abe E, Suzuki T, Kido T, Chiba M, Shimada Y: Spine-shortening vertebral osteotomy for tethered cord syndrome: report of three cases. Spine 34:E823-E825, 2009

38. Morimoto K, Takemoto O, Wakayama A: Spinal lipomas in children-surgical management and long-term follow-up. Pediatr Neurosurg 41:84-87, 2005

39. Nakamura K, Takeshita K, Akune T, Kawaguchi H, Kurokawa T: [Spinal shortening for tethered cord syndrome.] J Jpn Soc Spine Surg Relat Res 9 (1 Suppl):28, 1998 (Jpn)

40. O'Shaughnessy BA, Koski TR, Ondra SL: Reversal of neurologic deterioration after vertebral column resection by spinal cord untethering and duraplasty. Spine 33:E50-E54, 2008

41. Pang D, Wilberger JE Jr: Tethered cord syndrome in adults. J Neurosurg 57:32-47, 1982

42. Paradiso G, Lee GY, Sarjeant R, Fehlings MG: Multi-modality neurophysiological monitoring during surgery for adult tethered cord syndrome. J Clin Neurosci 12:934-936, 2005

43. Reyes-Sanchez A, Rosales LM, Miramontes VP, Garin DE: Treatment of thoracolumbar burst fractures by vertebral shortening. Eur Spine J 11:8-12, 2002

44. Samuels R, McGirt MJ, Attenello FJ, Garcés Ambrossi GL, Singh N, Solakoglu C, et al: Incidence of symptomatic retethering after surgical management of pediatric tethered cord syndrome with or without duraplasty. Childs Nerv Syst 25:1085-1089, 2009

45. Schoenmakers MA, Gooskens RH, Gulmans VA, Hanlo PW, Vandertop WP, Uiterwaal CS, et al: Long-term outcome of neurosurgical untethering on neurosegmental motor and ambulation levels. Dev Med Child Neurol 45:551-555, 2003

46. Singh K, Smucker JD, Gill S, Boden SD: Use of recombinant human bone morphogenetic protein-2 as an adjunct in posterolateral lumbar spine fusion: a prospective CT-scan analysis at one and two years. J Spinal Disord Tech 19:416-423, 2006 [Erratum in J Spinal Disord Tech 20:185, 2007]
47. Suk SI, Chung ER, Kim JH, Kim SS, Lee JS, Choi WK: Posterior vertebral column resection for severe rigid scoliosis. Spine 30:1682-1687, 2005

48. Suk SI, Chung ER, Lee SM, Lee JH, Kim SS, Kim JH: Posterior vertebral column resection in fixed lumbosacral deformity. Spine 30:E703-E710, 2005

49. Suk SI, Kim JH, Kim WJ, Lee SM, Chung ER, Nah KH: Posterior vertebral column resection for severe spinal deformities. Spine 27:2374-2382, 2002

50. Suk SI, Kim JH, Lee SM, Chung ER, Lee JH: Anterior-posterior surgery versus posterior closing wedge osteotomy in posttraumatic kyphosis with neurologic compromised osteoporotic fracture. Spine 28:2170-2175, 2003

51. Tanaka Y, Kokubun S, Ozawa H, Matsumoto F, Aizawa T, Hoshikawa T: [Spinal shortening for tethered cord syndrome.] Clin Orthop Surg 40:633-637, 2005 (Jpn)

52. Ueno H, Taguchi T, Kaneko K, Kawai S, Kihune M: [Spinal shortening for tethered cord of lumbosacral lipoma in adult. A case report.] Orthop Traumatol 50:340-342, 2001 (Jpn)

53. van Leeuwen R, Notermans NC, Vandertop WP: Surgery in adults with tethered cord syndrome: outcome study with independent clinical review. J Neurosurg 94 (2 Suppl):205-209, 2001

54. Wang B, Hong Y, Yi B, Yu X, Wang C: [Operative complications in tethered cord syndrome and their management.] Zhonghua Wai Ke Za Zhi 40:284-286, 2002 (Chinese)

55. Yamada S, Knerium DS, Mandybur GM, Schultz RL, Yamada BS: Pathophysiology of tethered cord syndrome and other complex factors. Neurol Res 26:722-726, 2004

56. Yamada S, Lonser RR: Adult tethered cord syndrome. J Spinal Disord 13:319-323, 2000

57. Yamada S, Siddiqi J, Won DJ, Kido DK, Hadden A, Spitalieri J, et al: Symptomatic protocols for adult tethered cord syndrome. Neurol Res 26:741-744, 2004

58. Yamada S, Won DJ: What is the true tethered cord syndrome? Childs Nerv Syst 23:371-375, 2007

59. Yamada S, Won DJ, Pezeshkpour G, Yamada BS, Yamada SM, Siddiqi J, et al: Pathophysiology of tethered cord syndrome and similar complex disorders. Neurosurg Focus 23(2):E6, 2007

60. Yamada S, Won DJ, Siddiqi J, Yamada SM: Tethered cord syndrome: overview of diagnosis and treatment. Neurol Res 26: 719-721, 2004

61. Yamada S, Zinke DE, Sanders D: Pathophysiology of "tethered cord syndrome.” J Neurosurg 54:494-503, 1981

Manuscript submitted March 8, 2010.

Accepted April 20, 2010.

Address correspondence to: Patrick C. Hsieh, M.D., Department of Neurological Surgery, University of Southern California, Keck School of Medicine, 1520 San Pablo Street, \#3800, Los Angeles, California 90033. email: phsieh@usc.edu. 